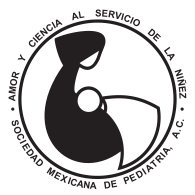

\title{
De pandemias, salud emocional y humanismo clínico
}

\author{
José Marcos Félix-Castro ${ }^{\ddagger * *}$ \\ ‡ Hospital General “Dr. Gaudencio García Garza”, Centro Médico Nacional La Raza, \\ Instituto Mexicano del Seguro Social. Universidad Anáhuac. Ciudad de México.
}

\section{DE LA CIENCIA A LA INCERTIDUMBRE DEL MIEDO}

En medio de esta pandemia, hace poco leía acerca de uno de los primeros médicos fallecidos en mi país a causa de este nuevo coronavirus, COVID-19. ${ }^{1}$ No presté mucha atención en cómo lo había contraído, en los síntomas presentados o las complicaciones desarrolladas; lo que más llamó mi atención del reportaje periodístico era que se centraba en la soledad de su sepelio, ya que sólo fue acompañado por una persona, un pariente cercano. No estuvo en una sala de velación y no tuvo cortejo fúnebre. Un médico especialista en urgencias médicas contagiado, con una familia en cuarentena y con una sociedad rodeada de miedo, ansiedad y preocupación por un futuro incierto. ${ }^{2}$

Por supuesto que también son de mi interés los aspectos clínicos y médicos que podamos obtener acerca de esta nueva pandemia. El conocimiento como el medio para superar la adversidad. Pero el reportaje acerca de este médico sin un duelo completo por su familia y sus amigos, soledad originada ya sea por precaución epidemiológica o por miedo ignorante, me lleva a reflexionar cómo este tipo de eventos nos afectan y nos cambian por dentro. El miedo, la angustia y el futuro incierto han llenado el tiempo de nuestras vidas de ideas que no son nuestras y nos han quitado la cotidianidad, y por momentos, nos han devuelto al origen de la vida del ser humano, la esperanza de sobrevivir.

\footnotetext{
*Correspondencia: JMFC, jmfelixc@hotmail.com

Conflicto de intereses: El autor declara que no tiene.

Citar como: Félix-Castro JM. De pandemias, salud emocional y humanismo clínico. Rev Mex Pediatr. 2020; 87(1):3-6. doi: $10.35366 / 93260$

[About pandemics, emotional health and clinical humanism]
}

\section{LO NO APRENDIDO}

En teoría, debemos aprender de las calamidades y las catástrofes humanas, sin embargo, no lo hemos hecho del todo. Existe evidencia de que aprender de las experiencias vividas puede ser limitado, incluso en situaciones de riesgo. Algunos reportes nos hacen ver que en brotes previos por coronavirus no hemos articulado de forma adecuada la vigilancia de riesgos en situaciones de emergencia, como con el síndrome respiratorio de Oriente Medio (MERS) y el síndrome respiratorio severo agudo (SARS). Los resultados del aprendizaje entre estos dos brotes y el actual desalientan ya que, al parecer, no hemos evaluado apropiadamente los riesgos sanitarios, lo que ha llevado a su propagación por factores sociales, culturales, médicos y epidemiológicos. ${ }^{3}$

\section{EL IMPACTO NO INFECCIOSO DE UNA PANDEMIA}

Un brote infeccioso de consecuencias globales conlleva riesgos, tanto en salud pública como en la economía y la sociedad, a nivel poblacional e individual. Y aunque regularmente se obtienen avances científicos, poco se estudia de los alcances mentales y emocionales. Por lo que cobran alta importancia los expertos en salud mental, de tal forma que psiquíatras y psicólogos deben colaborar para disminuir o limitar el desgaste emocional del personal de salud y de los enfermos. ${ }^{4}$

Algunos de los aspectos en este rubro a tomar en cuenta ${ }^{4}$ incluyen:

1. Timing con modelos epidemiológicos productivos que permiten predecir, planear y prepararse para todo el proceso. 
2. Desgaste emocional y mental de los trabajadores de la salud, incluyendo desarrollo de estrés postraumático por sus pacientes y por los cuidadores.

3. Distanciamiento social en el cual las diversas separaciones o confinamientos de los individuos les afectan de forma diversa.

4. Secuelas psiquiátricas producto de la enfermedad o su tratamiento.

5. Contagio conductual, en el cual se incluyen preocupaciones, miedos y malas concepciones de lo que se vive en medio de una pandemia (los trabajadores de la salud deberíamos estar preparados para enfrentarlos).

6. Deficiencias de los servicios de salud, incluyendo falta de personal para atender problemas psicoemocionales de los propios trabajadores.

Dentro de esta pandemia, no debemos dejar de lado el aspecto de la salud mental relacionado con las ideas, creencias y la "insanidad" de las emociones y los pensamientos de quienes sufren o están en riesgo de padecer infección por COVID-19. Estos aspectos son tan profundos que ya son parte de nuestra cultura de diversión, como ejemplo las películas de infecciones devastadoras o de holocaustos zombis.

En muchas ocasiones, la sociedad se comporta de acuerdo con sus principios más básicos de supervivencia, desarrollando ansiedad masiva e histeria colectiva que finalizan con decisiones incontrolables y equivocadas, actuando como "muertos vivientes/zombis" a los cuales les fue separada el alma y la mente del cuerpo. Por lo que, desafortunadamente, nos quedamos con los reflejos y anulamos las reflexiones. Varias cosas se modifican en medio de todo esto, la normalidad -lo cotidiano- rompiendo con el sentido y la realidad de la vida. Y cuando se restauran estos procesos quedan sentimientos reprimidos e incluso amnesia de lo experimentado. ${ }^{4}$

Un aspecto de la psicología que se estudia de una pandemia es el término de contagio (procedente de la palabra latina contagio, "del contacto"), y con ello se forma una teoría que impacta las emociones y las conductas de los individuos. Es decir, el efecto sobre una persona. En estas crisis hay tintes de anonimato por parte de las masas, sin que exista conciencia de las consecuencias de sus actos sobre los individuos; además, se encuentra la disposición del individuo a sacrificarse por el pensamiento colectivo, en lugar de la independencia de su pensamiento. Así, el individuo se engancha a la masa, pensando y actuando en colectividad, lo cual, rodeado de ignorancia, tiende a ser muy peligroso.
El resultado de lo anterior puede derivar en dos procesos psicológicos que afectan a los individuos. El primero es el contagio emocional, en el cual el estado anímico y el afecto se modifican. El segundo es el contagio conductual, que implica estar propensos a copiar las decisiones de la masa. Estos conceptos apoyan que, además de una emergencia sanitaria, existe una epidemiología emocional. ${ }^{4}$ En ocasiones, no es necesario tener una afectación psicológica o psiquiátrica, simplemente no se alcanza el estándar de felicidad esperado. ${ }^{5}$

Pero se debe tener en cuenta que todos los afectados en una pandemia, población general o personal de salud, pueden tener antecedentes o condiciones preexistentes de alteraciones psicoemocionales que se manifiestan durante una pandemia. Lo que nos lleva a meditar que el desgaste normal de los profesionales de la salud puede agravarse, por lo que requieren vigilancia y apoyo continuo. ${ }^{6}$

\section{PERSONAL DE LA SALUD, COVID-19 Y LO QUE CAMBIA}

Cuando en China inició la propagación de este nuevo coronavirus, lo aprendido con los virus previos (MERS/ SARS) dictaba que las decisiones y las acciones deberían ser tomadas de manera rápida, tanto para encontrar una forma efectiva de detener la epidemia, como para desarrollar una vacuna, o para limitar el número de pacientes con complicaciones.

Sin embargo, muchas preguntas ocasionaban ansiedad y angustia, pero otras miedo. ¿Qué pasará en África con infraestructura tan precaria?, ¿estarán dispuestos los demás países, que ya tienen sus propios problemas, para ayudar a África o cualquier otro país pobre? Y este miedo llevó a diversos países a tratar de poner barrera para evitar la propagación del virus. Además, a diferencia de brotes epidémicos previos, la alta cobertura de medios y en redes sociales permitió tener información a veces poco fidedigna, lo cual aumentó las dudas y la incertidumbre. Y agreguemos que en medio de una pandemia se afecta el aspecto económico, donde las pérdidas financieras y el riesgo del desempleo también impactan negativamente a las personas. ${ }^{7}$

Hay diferentes tipos de miedo, en lo individual, la comunidad y a nivel global. Respuestas y miedos que podrían ser abatidas con solidaridad y cooperación. ${ }^{8}$ De forma inicial, en China se encontraron problemas psicológicos severos hasta en 53.8\% de la población, incluyendo depresión grave, ansiedad y altos niveles de estrés e incluso culpa. 
Se conoce que quienes responden primero, como el personal de ambulancias o trabajadores de la salud, son quienes más se afectan al temer contagiarse y contagiar a sus seres queridos. Agreguemos que se desarrolla disonancia y conflictos internos cuando falla el balance entre el deber profesional y el altruismo, contra los miedos personales. Personal de salud en terapias intensivas y guardias de aislamiento son los más afectados, incluso se ha establecido que médicos solteros se ven psiquiátricamente más afectados que enfermeras casadas, tomando en cuenta que otros factores pueden agravarlos, tales como falta de soporte social, falla en la comunicación y ausencia de entrenamiento. ${ }^{7}$

Un estudio dirigido en medio de la pandemia de COVID-19 en China reveló que ser una mujer con un título profesional intermedio (enfermera, por ejemplo) se asocia con depresión, ansiedad y estrés. Asimismo, trabajar en un hospital de segundo nivel a comparación de un hospital de alta especialidad se asocia con síntomas más severos de depresión y ansiedad. Además de que trabajar en lugares con mayores casos genera procesos más profundos. ${ }^{9}$

\section{SALVANDO LA NATURALEZA HUMANA}

Hace poco tiempo publiqué en mi Facebook, un comentario de un portal llamado Pedagogía. Los autores asumen el principio de la civilización (que puede ser también del humanismo), tenía su génesis en un lugar donde se encontró un fósil, con un fémur roto recuperado. Y es que este hueso soldado implica que alguien en algún momento cuidó de él, es decir, alguna persona se acercó con agua, comida y lo protegió, porque nadie sobrevive con una pierna rota por sí solo. ${ }^{10}$ Esta pandemia nos está demostrando quiénes somos, qué somos, pero sobre todo, qué tanto estamos dispuestos a hacer o no hacer por los demás. Los ejemplos que están aquí, adultos mayores, padres, madres, abuelas y abuelos, así como las personas jóvenes infectadas, no pueden salir a la calle, no pueden ser visitados. Alguien tiene que ayudarlos. La manada no los puede dejar atrás...

Singapur luchó contra estos cambios psicológicos y psiquiátricos con una estrategia de defensa total, lo cual fue crucial para mantener la fe y la confianza de la población. Asimismo, el personal desarrolló resiliencia frente a la crisis. Las conferencias de prensa del ministro de salud y el control de las noticias falsas en medios masivos y redes sociales apoyaron esta causa. A la par, policlínicas y hospitales desarrollaron consultas de psiquiatría y psicoterapia como un servicio de consuelo a las familias. Para facilitar este proceso, sugieren la implementación de planes donde se incluya la identificación de riesgo, se realice tamizaje para morbilidades psiquiátricas, se intervenga psicológicamente con programas específicos y se apoye más a los trabajadores de la salud para enfrentar esta y futuras pandemias. ${ }^{7}$

Encontrar a personas vestidas con trajes aislantes atendiendo y cuidando a otras personas con el riesgo de que éstas mismas contagien a otros, verdaderamente es un llamado a la conciencia. Todos los días vemos imágenes de médicos y enfermeras entregándose al estrés y el riesgo del virus, a pesar de las carencias. Sin embargo, independientemente de lo adverso y exhaustivo que puede ser cuidar al enfermo bajo condiciones precarias, hay un denominador común en todos los reportajes que salen a la luz en medio de esta pandemia: "este virus nos ha mantenido juntos, nos une" lo que es explicado a través de la resiliencia, la cual también nos fortalece ante el miedo y el pánico. ${ }^{11}$

En contraparte, no debemos dejar pasar que a causa de esta epidemia han existido también brotes de discriminación. Por ejemplo, en un inicio la población de China fue sujeta a escarnio público. Y recientemente en nuestro país el mismo personal de salud está viviendo esta discriminación, lo cual seguramente es resultado de la ignorancia de una comunidad que tiene más miedo que conocimiento. De esta forma, es necesario el apoyo entre nosotros, en la calidez de las relaciones uno a uno, aunque sea a distancia.

Está bien establecida la forma en que, en medio del sufrimiento y del dolor, podemos encontrar apoyo y compasión mediada por la empatía. La misma influencia que ejerce la adversidad sobre los individuos, los modifica para el resto de la vida. No podemos evitar que algo duela, pero si nos topamos con empatía y compasión habrá motivación social. La compasión es un elemento de la funcionalidad social adaptativa, que nos conduce a ayudar, formando grupos de ayuda altruista que se caracterizan por su amabilidad, generosidad y cooperación, los cuales emergen en situaciones adversas de enfermedad y en las catástrofes. ${ }^{12}$

\section{ENSEÑANDO LO APRENDIDO}

Buscar en los pacientes sus necesidades emocionales y espirituales es un aliciente, y no somos los únicos en estos procesos. Existen profesionales que tienen bien establecidos los parámetros a cubrir desde un punto de vista holístico, como los procesos de enfermería que incluyen evaluación de estado de salud, comunicación, el cuidado espiritual y de las emociones de los pacientes. ${ }^{13}$ 
El personal de salud, en general, teme afrontar y compartir el propio dolor o angustia con nuestros pares o pacientes. Sentimos miedo, probablemente por desconocimiento, porque en este momento una verdad innegable es que todos tenemos terror de enfermar y contagiar, de enfermar y agravar, y por supuesto, de morir. En muchas ocasiones, hacemos creer que superamos esos miedos; por ejemplo, al crear campañas en las cuales nos mostramos sufriendo y lidiando emocionalmente con esta pandemia, o bien, considerándonos como héroes y comparándonos con superhéroes imaginarios. Pero en realidad sólo somos personas acompañando a otras personas en su proceso de enfermedad.

\section{LA HUMILDAD COMO UN PARÁMETRO A ENSEÑAR}

Para todos aquellos que tenemos que ver con la educación, con la enseñanza de la medicina o de las ciencias de la salud es un momento de reflexión. Estamos frente a una de las pandemias más grandes de todos los tiempos, la cual es la que ha tenido mayor cobertura de medios y de redes electrónicas, por lo que los procesos educativos se hacen más complejos, ¿cómo hacer que el dolor nos enseñe?, ¿cómo hacer para que la pérdida de todas estas vidas, nos eduque y nos forme?, ¿se puede evaluar la empatía entre los alumnos en este momento?, ¿qué parámetros tenemos que medir o qué rúbricas tendremos que utilizar? Es verdad, tengo más preguntas que respuestas, pero también me da motivos para buscar más. La educación es el medio que nos permite no dejar que las cosas pasen y se olviden, hay experiencias que se tienen que quedar, esta epidemia debe ser una de ellas.

En situaciones como esta pandemia nos encontramos con la oportunidad de desarrollar el profesionalismo, el cual es parte del humanismo, mismo que en este documento he decido llamar humanismo clínico, ya que no sólo concentra el quehacer de médicos y enfermeras, sino de todo el personal que tiene contacto con el paciente y que le apoya y acompaña a lo largo de su enfermedad. Administradores hospitalarios, químicos, laboratoristas, técnicos radiólogos y de inhaloterapia, personal de limpieza, personal de conservación de hospitales, nutriólogos, psicólogos, trabajadores sociales, asistentes médicos, y tantos más, que estoy seguro de que, con su trato digno y amable, fortalecen los lazos en medio de esta crisis y que son parte de este humanismo clínico. A pesar de las carencias en sistemas de salud y por encima de nuestros miedos y preocupaciones, con base en los valores más profundos que nos definen como personas y que nos agrupan como humanidad, atendemos y ayudamos a nuestros pacientes. Humanos ayudando a otros humanos, "mientras la pierna rota se recupera". Lo único que nos protege de los agresores externos e internos somos nosotros mismos.

No lo voy a negar -en términos estadísticos-, para esta pandemia, lo peor tal vez aún está por llegar, pero espero que también lo mejor. Mujeres y hombres encontraremos en ayudar a los demás un motivo más para hacer y vivir en un mundo mejor.

\section{REFERENCIAS}

1. Aragón-Nogales R, Vargas-Almanza I, Miranda-Novales MG. COVID-19 por SARS-CoV-2: la nueva emergencia de salud. Rev Mex Pediatr. 2019; 86(6): 213-218. doi: 10.35366/91871.

2. Agencia Reforma. Sepultan en solitario a médico del IMSS. El Mañana [Internet]. Jueves 2 de abril de 2020. [Acceso 4 de abril de 2020]. Disponible en: https://www.elmanana.com/sepultan-ensolitario-a-medico-del-imss-coronavirus-sepelio-doctor/5060426

3. Peeri NC, Shrestha N, Rahman MS, Zaki R, Tan Z, Bibi S et al. The SARS, MERS and novel coronavirus (COVID-19) epidemics, the newest and biggest global health threats: what lessons have we learned? Int J Epidemiol. 2020 Feb 22. pii: dyaa033. doi: 10.1093/ ije/dyaa033.

4. Huremovic D. Psychiatry of pandemics. Switzerland: Springer;2019.

5. Li S, Wang Y, Xue J, Zhao N, Zhu T. The impact of COVID-19 epidemic declaration on psychological consequences: a study on active Weibo users. Int J Environ Res Public Health. 2020; 17(6). pii: E2032. doi: 10.3390/ijerph17062032.

6. Perlis $\mathrm{RH}$. Exercising heart and head in managing coronavirus disease 2019 in Wuhan. JAMA Netw Open. 2020; 3(3): e204006.

7. Ho CS, Chee CY, Ho RC. Mental health strategies to combat the psychological impact of COVID-19 beyond paranoia and panic. Ann Acad Med Singapore. 2020; 49(3): 1-3.

8. Kelvin DJ, Rubino S. Fear of the novel coronavirus. J Infect Dev Ctries. 2020; 14 (1): 1-2.

9. Lai J, Ma S, Wang Y, Cai Z, Hu J, Wei N et al. Factors associated with mental health outcomes among Health Care Workers Exposed to Coronavirus Disease 2019. JAMA Netw Open. 2020; 3(3): e203976.

10. Pedagogía. 18 marzo 2020. Facebook. Disponible en: https://www. facebook.com/emmanuelrdz02/? tn__=kCH-R\&eid=ARD7d-ny 1KLNZugC4rNju_95Csa2L5rn2kNt $\overline{\mathrm{kp}}$ IIUWyvTa0gYoQhVEPY nj6_fD9_ON_PVSnrmKB9-db\&hc_ref=ARSS_nsi88tpFphTZ W4MOLfmfOT9tt953mVbcE0fBO3xq8uBxtqOGttL8QzsXjJABX 0\&fref=nf\&_xts_[0]=68.ARDIJ6leLjv2GpFmjxVjjsZZeZWgG TCCt4jjw 4 wtRCPxriofgFVObDq_seG01LwaZKf TveqIEAfEXx7rialOtzw2iqVKSRIG-GYZ-CIy3IXtXCQVYE 8xIYCIVcFBzMUeGPzDSHrPfTkbAFzmm O33DtiESpJtb5XGntzuzaHs6luDWIH1rqv60BHB7QcHqINBNr2 Q54Rtwi20KApb8e48aORBTMpd6denBJFmLAVbaeP83Q7Dr11 T7mhn4jGwg0TeMct7CuPjtmLX1mtzhV5dGxRogXCkidjCPfaaoK 4hCFghb9DgpWnUsxRjk1OHg1iZekuZM-EnV8aj56ZBn

11. Smith GD, Ng F, Ho Cheung Li W. COVID-19: Emerging compassion, courage and resilience in the face of misinformation and adversity. J Clin Nurs. 2020; 29(9-10): 1425-1428.

12. Lim D, DeSteno D. Suffering and compassion: The links among adverse life experiences, empathy, compassion, and prosocial behavior. Emotion. 2016; 16(2): 175-182.

13. Delgado C. Meeting clients' spiritual needs. Nurs Clin NAm. 2007; 42: 279-293. 